\title{
Low estradiol levels escalate menopausal symptoms leading to mild cognitive impairment in postmenopausal women
}

Andon Hestiantoro, ${ }^{1}$ Shanty Olivia Jasirwan, ${ }^{1}$ Martina Wiwie, ${ }^{2}$ Amalia Shadrina, ${ }^{1}$ Nurhadi Ibrahim,${ }^{3}$ Brilliant Putri Kusuma Astuti $^{1}$

pISSN: 0853-1773• elSSN: 2252-8083 https://doi.org/10.13181/mji.v28i1.2447 Med J Indones. 2019;28:40-6

Received: January 10, 2018

Accepted: January 29, 2019

Author's affiliations:

${ }^{1}$ Department of Obstetrics and Gynecology, Faculty of Medicine, Universitas Indonesia, Cipto Mangunkusumo Hospital, Jakarta, Indonesia, ${ }^{2}$ Department of Psychiatry, Faculty of Medicine, Universitas Indonesia, Cipto Mangunkusumo Hospital, Jakarta, Indonesia, ${ }^{3}$ Department of Physiology, Faculty of Medicine Universitas Indonesia, Cipto Mangunkusumo Hospital, Jakarta, Indonesia

\section{Corresponding author:}

Andon Hestiantoro

Department of Obstetrics and

Gynecology, Faculty of Medicine,

Universitas Indonesia, Cipto

Mangunkusumo Hospital,

Jalan Diponogoro No.71, Kenari, Senen,

Central Jakarta 10310, DKI Jakarta,

Indonesia

Tel/Fax: +62-21-3928720/

+62-21-3928719

E-mail: hestiantoro@gmail.com

\begin{abstract}
BACKGROUND Women in menopause experience dramatic alterations in gonadal hormone concentrations, including diminished estradiol levels. It has been hypothesized that these hormonal changes may be responsible for the occurrences of menopausal symptoms, such as hot flushes, sleep disruption, night sweats, and irritability, as well as mild cognitive impairment $(\mathrm{MCl})$ in postmenopausal women. Therefore, this study was aimed to determine if there is any association between hormonal changes and menopausal symptoms, including $\mathrm{MCl}$ in postmenopausal women.
\end{abstract}

METHODS A total of 245 postmenopausal women were recruited for this crosssectional study and classified into 2 groups; $\mathrm{MCl}$ and non- $\mathrm{MCl}$ groups. Diagnosis of $\mathrm{MCl}$ was made using the modified Petersen criteria. Variables such as subjects' age, duration of menopause, menopausal symptoms, anthropometric status, hormone levels, and cognitive status were assessed and statistically analyzed.

RESULTS Of the 245 subjects enrolled in this study, $53.9 \%$ had $\mathrm{MCl}$. Multivariate analysis found that sleep disruption and estradiol levels were independent risk factors of $\mathrm{MCl}$ in postmenopausal women. No significant correlation was found between menopausal symptoms and estradiol concentration.

CONCLUSIONS Low estradiol levels were associated with higher risks of experiencing menopausal symptoms and $\mathrm{MCl}$. Sleep disruption and estradiol levels were the most influential factors in the development of $\mathrm{MCl}$ in postmenopausal women.

KEYWORDS estradiol, menopausal symptoms, mild cognitive impairment
Menopause is a natural biological process that occurs in every woman as a signal of reproductive senescence. $^{1}$ This condition is diagnosed retrospectively and defined as the cessation of spontaneous menstruation for 12 months in a row. Women are born with a finite number of oocytes. These eggs are depleted gradually over the course of female reproductive years through ovulation and atresia. When women reach menopause, there is a complete depletion in the number of ovarian follicles, making it impossible for the ovary to counteract the actions of FSH and $\mathrm{LH}$. Along with the diminution of ovulation, estrogen production drastically diminishes. This process does not happen at a particular timepoint, instead, it takes years to complete. ${ }^{2}$

Several symptoms associated with the decline in estrogen levels during the climacteric period have been reported. ${ }^{3}$ These symptoms are thought to cause a significant reduction in the quality of life in about $80 \%$ of menopausal women. ${ }^{4}$ An earlier study reported that the most frequently experienced symptoms during the menopausal period were hot flushes and night 
sweats. Hot flushes and night sweats are considered as primary menopausal symptoms. ${ }^{1}$ In Indonesia, the most frequently experienced and reported symptoms of menopause were night sweats (54.2\%), sleep disruption (61\%), irritability (28.8\%), mood swings (39\%), difficulty concentrating (49.2\%), and hot flushes (5.1\%). ${ }^{5}$ These symptoms led to social impairment and reduction of overall quality of life.

Hot flushes are spontaneous sensations of warmth in the chest, neck, and face that usually last less than $5 \mathrm{~min}$. They may be triggered by environmental temperature, stress, or foods. ${ }^{2}$ Night sweats usually result in sleep disruptions. Clinical manifestations of menopause including vasomotor, urogenital, and psychogenic symptoms are highly associated with menopausal status and psychosocial factors. ${ }^{2}$ The pathophysiology underlying this condition is thought to be related to low estrogen levels, as well as high gonadotropin levels that affect endorphin concentrations in the hypothalamus. ${ }^{2}$

Although not regarded as a cardinal symptom of menopause, cognitive dysfunction is a commonly reported complaint among women transitioning into menopause. Cardinal symptoms of menopause are considered to be important contributors to the deterioration in cognitive function observed in postmenopausal women. Significant reduction in estrogen concentration (particularly estradiol) in menopausal women may affect cognitive function through several mechanisms, including the loss of estrogen's protective functions, its anti-toxic properties, neural injury, and neural death. ${ }^{5}$ The presence of cognitive impairment in menopausal women increases the future risk of developing Alzheimer's disease. Alzheimer's disease is the deadliest and most debilitating neurodegenerative disease. It progressively causes memory loss resulting from the disruption of neural metabolism, communication, and the regeneration process. Previous epidemiological studies found that both prevalence and incidence of Alzheimer's disease were disproportionately high in menopausal women. 5 This gender-related disparity suggests that reproductive hormones are important etiological factors for cognitive impairments, such as Alzheimer's disease. ${ }^{5}$

Individuals with cognitive function status ranging between normal cognitive aging and very early dementia were categorized as having mild cognitive impairment $(\mathrm{MCl}) .^{5}$ Earlier studies have reported a high prevalence of $\mathrm{MCl}$ in Indonesia. ${ }^{5}$ Early detection of $\mathrm{MCl}$ is an important preventive measure for Alzheimer's disease, which requires complicated treatments and has an unfavorable prognosis. As previously stated, reproductive hormones, particularly estrogen, play a significant role in the maintenance of normal cognitive functioning. The protective properties of estrogen against neurodegeneration have been well described. Estrogen is important for maintaining the balance between pro-inflammatory and anti-inflammatory factors in human brain cells. It also enhances the neurochemical actions of several neurotransmitter systems which are severely injured in Alzheimer's disease, including cholinergic, monoaminergic, GABAergic, serotonergic, and glutaminergic systems. Estrogen defends neurons against oxidative stress and toxicity that causes apoptosis, neural injury, and neural death. Estradiol is also an important factor in the regulation of neural activities in several brain areas responsible for the formation of memories, such as the hippocampus and prefrontal cortex. Furthermore, in menopausal women, the risk of impaired cognitive function under hypoestrogenic conditions increases with the existence of comorbidities such as hypertension, diabetes mellitus, dyslipidemia, and low cognitive reserves. ${ }^{6}$

Therefore, it is expected that the decline in estrogen concentrations may induce cognitive impairment, including $\mathrm{MCl}$ and Alzheimer's disease. ${ }^{7}$ This study was aimed to find the correlation between menopausal symptoms and hormonal changes, as well as any association with $\mathrm{MCl}$.

\section{METHODS}

\section{Study design}

This cross-sectional study was conducted from June to October 2016 in Jakarta. A total of 245 women were recruited. The inclusion criteria for this study were female, postmenopausal, and aged $<75$ years old. Women who had not completed at least 9 years of education, or self-reported use of hormone therapy, who were active smokers, alcoholics, or suffering from chronic diseases were excluded from this study. All subjects were informed about the study protocol and required to provide written consent, before enrollment in the study. This process was completed before participants were interviewed and underwent physical examination. 
The variables assessed in this study were duration of menopause, menopausal symptoms such as sleep disruption, hot flushes, night sweats, and mood swings; body mass index (BMI), hormone levels such as $\mathrm{LH}$ and estradiol, as well as cognitive status. Cognitive status was assessed using a scoring system proposed by Dr. Martina Wiwie, SpKJ(K). ${ }^{8}$ This test is a modified version of the Petersen Criteria, which has been widely used for the diagnosis of $\mathrm{MCl}$. It is scored from the set of data obtained from subjects and consists of the Geriatric Depression Scale score, type 2 diabetes mellitus, impaired glucose tolerance, dyslipidemia, Rey-Osterrieth complex figure test, Trail Making Test B (TMT B), and the digit span backward test. Each parameter was assigned a value of 0 or 1 , according to the results of the test. The results were then computed according to the index of each parameter. A total score of 120 was used as a cut-off score. A total score of 120 or more was indicative of the presence of $\mathrm{MCl}^{8}$

\section{Statistical analysis}

All data were entered into distribution table and analyzed using the Statistical Package for the Social Sciences software version 22. Univariate analysis was performed to study the data distribution. Bivariate analysis was performed to compare the association between each variable and $\mathrm{MCl}$. A p-value of 0.05 or less is considered significant. Variables with a p-value less than 0.25 in bivariate analysis were further referred for multivariate logistic regression analysis.

\section{Ethics approval}

Every participant in this study was informed about the study protocol and has provided written consent. The ethics of this study was reviewed and approved by Ethics Committee of the Faculty of Medicine Universitas Indonesia/Cipto Mangunkusumo Hospital, with reference number of 487/UN2.F1/ETIK/V/2017.

\section{RESULTS}

A total of 245 postmenopausal women in Jakarta participated as subjects in this study. Subjects were interviewed about their menopausal period and menopausal symptoms such as hot flushes, night sweats, sleep disruption, and irritability. Subjects also underwent anthropometric measurements to assess the subject's body weight, height, and BMI. Venous blood samples were drawn from each subject to assess hormone concentrations. A series of tests were conducted to evaluate every subject's cognitive status. The mean (SD) age of subjects who participated in this study was 59.52 (6.8) years old. Menopausal duration was greater than 10 years in almost half of the subjects (49.4\%).

Of the 245 participants who underwent medical history taking an interview, approximately $28.6 \%$ subjects reported that they had hot flushes, $24.5 \%$ reported sleep disruptions, $24.9 \%$ had night sweats, and $20.8 \%$ experienced irritability. These subjects were further classified into 2 groups according to the results of their cognitive function test. Of the 245 subjects, 132 subjects $(53.9 \%)$ were categorized in the $\mathrm{MCl}$ group and the other 113 subjects (46.1\%) were placed in the non- $\mathrm{MCl}$ group. Details of subjects' characteristics are presented in Table 1.

Subjects in the $\mathrm{MCl}$ group showed a statistically lower concentration of estradiol, compared to the subjects in the non- $\mathrm{MCl}$ group $(\mathrm{p}=0.037)$. Menopausal

Table 1. Characteristics of study subjects $(n=245)$

\begin{tabular}{lc}
\hline Characteristics & Value, $\mathrm{n}(\%)$ \\
\hline Age (years), mean (SD) & $59.52(6.8)$ \\
\hline $\mathrm{BMI}\left(\mathrm{kg} / \mathrm{m}^{2}\right)$, mean (SD) & $23.79(3.57)$ \\
\hline Estradiol levels, median (min-max) & $12(11.8-113.8)$ \\
\hline LH levels (ng/dl), mean (SD) & $68.3(28.56)$ \\
\hline Cognitive score & \\
\hline MCl positive & $132(53.9)$ \\
\hline MCl negative & $113(46.1)$ \\
\hline Menopause duration & \\
\hline$>10$ years & $119(49.4)$ \\
\hline $5-10$ years & $77(32)$ \\
\hline$<5$ years & $45(18.7)$ \\
\hline Hot flushes & $70(28.6)$ \\
\hline Yes & $175(71.4)$ \\
\hline No & \\
\hline Sleep disruption & $60(24.5)$ \\
\hline Yes & $185(75.5)$ \\
\hline No & \\
\hline Night sweats & $184(75.1)$ \\
\hline Yes & $51(20.8)$ \\
\hline No & $194(79.2)$ \\
\hline Yrritability & \\
\hline No & \\
\hline
\end{tabular}

$\mathrm{BMI}=$ body mass index; $\mathrm{LH}=$ luteinizing hormone; $\mathrm{MCl}=$ mild cognitive impairment 
symptoms, such as hot flushes, sleep disruption, night sweats, and irritability were more frequent in subjects with $\mathrm{MCl}$. Significant differences were observed in sleep disruption $(p=0.026)$ and irritability complaints ( $p=0.042$ ) between subjects in the $\mathrm{MCl}$ group and the non-MCl group (Table 2).

Correlation analysis was performed to quantify the association between menstrual symptoms and cognitive function score. None of the 4 menstrual symptoms assessed in this study showed a statistically significant correlation with cognitive function score. However, significant correlations were observed between menstrual symptoms. Hot flushes showed positive weak correlations with sleep disruption $(p=0.024, r=0.144)$ and night sweats $(p=0.013, r=0.158)$. Sleep disruption showed positive weak correlations with night sweats $(p=0.000, r=0.265)$ and irritability $(p=0.002, r=0.199)$.

Several variables, including menstrual symptoms, estradiol and LH concentrations, were further examined using logistic regression for multivariate analysis. The results of this analysis revealed that sleep disruption and estradiol concentration were independent risk factors for $\mathrm{MCl}$ in postmenopausal women (Table 2).

\section{DISCUSSION}

The aimed of this study was to evaluate the association between hormonal changes, menopausal symptoms, and $\mathrm{MCl}$ in postmenopausal women. This research subject is significant because hot flushes, night sweats, irritability, sleep disruption, and cognitive impairment are some of the most commonly reported complaints among postmenopausal women. ${ }^{9}$ Along with these clinical symptoms, postmenopausal women also experience alterations in reproductive hormone concentrations, particularly estradiol. Therefore, it can be suggested that symptoms manifested in postmenopausal women are related to the alterations in estradiol concentration.

Table 2. Bivariate and multivariate analyses

\begin{tabular}{|c|c|c|c|c|c|c|}
\hline \multirow{2}{*}{ Variables } & \multirow{2}{*}{$\begin{array}{c}\mathrm{MCl} \text { positive, } \\
\mathrm{n}(\%) \\
(\mathrm{n}=132)\end{array}$} & \multirow{2}{*}{$\begin{array}{c}\mathrm{MCl} \text { negative, } \\
\mathrm{n}(\%) \\
(\mathrm{n}=113)\end{array}$} & \multicolumn{2}{|c|}{ Bivariate analysis } & \multicolumn{2}{|c|}{ Multivariate analysis } \\
\hline & & & OR (Cl 95\%) & $\mathrm{p}$ & OR (Cl 95\%) & $\mathrm{p}$ \\
\hline \multicolumn{7}{|l|}{ Hot flushes } \\
\hline Yes & $41(58.6)$ & $29(41.4)$ & $1.3(0.74-2.28)$ & 0.396 & & \\
\hline No & $91(52.0)$ & $84(48.0)$ & & & & \\
\hline \multicolumn{7}{|l|}{ Sleep disruption } \\
\hline Yes & $40(66.7)$ & $20(33.3)$ & $2.02(1.09-3.71)$ & 0.026 & $1.735(0.90-3.33)$ & 0.098 \\
\hline No & $92(49.7)$ & $93(50.3)$ & & & & \\
\hline \multicolumn{7}{|l|}{ Night sweats } \\
\hline Yes & $37(60.7)$ & $24(39.3)$ & $1.44(0.80-2.60)$ & 0.239 & $1.32(0.69-2.51)$ & 0.393 \\
\hline No & $95(51.6)$ & $89(48.4)$ & & & & \\
\hline \multicolumn{7}{|l|}{ Irritability } \\
\hline Yes & $34(66.7)$ & $17(33.3)$ & $1.96(1.02-3.74)$ & 0.042 & $1.72(0.88-3.39)$ & 0.111 \\
\hline No & $98(50.5)$ & $96(49.5)$ & & & & \\
\hline \multicolumn{7}{|l|}{ Menopause duration } \\
\hline$>10$ years & $63(55.8)$ & $50(44.2)$ & $0.71(0.37-1.38)$ & 0.209 & & \\
\hline $5-10$ years & $42(55.3)$ & $34(44.7)$ & $0.91(0.45-1.86)$ & 0.124 & & \\
\hline$<5$ years & $17(40.5)$ & $25(59.5)$ & 1.00 & & & \\
\hline Age (years), mean (SD) & $59.19(6.62)$ & $59.9(6.95)$ & $0.71(1.01-2.42)$ & 0.42 & & \\
\hline BMI $\left(\mathrm{kg} / \mathrm{m}^{2}\right)$, mean (SD) & $23.95(3.83)$ & $23.6(3.25)$ & $0.34(0.55-1.24)$ & 0.45 & & \\
\hline $\begin{array}{l}\text { Estradiol levels, median } \\
\text { (min-max) }\end{array}$ & $11.80(11.8-27.2)$ & $12.9(11.8-113.8)$ & & 0.037 & $0.93(0.88-0.99)$ & 0.019 \\
\hline LH levels (ng/dl), mean (SD) & 70.77 (30.63) & $65.41(25.76)$ & $5.35(1.83-12.55)$ & 0.144 & $1.00(0.99-1.01)$ & 0.151 \\
\hline
\end{tabular}

$\mathrm{MCl}=$ mild cognitive impairment; $\mathrm{OR}=$ odds ratio; $\mathrm{Cl}=$ convidence interval; $\mathrm{BMI}=$ body mass index; $\mathrm{LH}=$ luteinizing hormone 
In contrast to Zeki Al Hazzouri et al, ${ }^{10}$ the average age of subjects in the $\mathrm{MCl}$ group was lower than that of subjects in the non- $\mathrm{MCl}$ group. However, this difference was not statistically or clinically significant. Amore et al' $^{1}$ found that age alone was not a major risk factor for $\mathrm{MCl}$ in postmenopausal period. However, when combined with other factors such as low education level, financial difficulties, unemployment, and sedentary lifestyle, it might affect the development of $\mathrm{MCl}$. Earlier studies have also shown that a hostile environment could be a significant stressor and may induce depression.

Subjects in the $\mathrm{MCl}$ group were found to have significantly lower estradiol levels compared to subjects in the non- $\mathrm{MCl}$ group. The protective properties of estradiol against neurodegeneration and loss of cognitive function have been well described. Therefore, its decline in postmenopausal conditions was considered as important risk factor for the development of cognitive impairment in the serotonergic and noradrenergic pathways." Several studies by Hestiantoro et $\mathrm{al}^{5}$, Rossmanith et $\mathrm{al}^{11}$, and Santoro et $\mathrm{al}^{12}$ reported that a decline in estradiol serum concentration in postmenopausal women could significantly increase the risk of $\mathrm{MCl}$.

Aside from its association with $\mathrm{MCl}$, the authors observed a huge variability in estradiol concentration. It is not unusual for postmenopausal women to have low concentrations of estradiol. However, we found that some of the subjects had significantly high estradiol concentration. A possible explanation for this might be that estradiol concentration is not solely influenced by its production by ovarian tissue. Although estradiol is primarily produced by follicles in ovary, it is also secreted by other tissues, such as adrenal glands, fat, liver, breasts, and brain cells. The synthesis of estradiol by these tissues is affected by several factors, one of them is obesity. Obesity or excess body fat causes an increase in aromatase production. Aromatase is the enzyme responsible for the conversion of male hormones (androstenedione or testosterone) into estrone or estradiol. The mean (SD) BMI of our subjects was 23.79 (3.57) kg/m², which was classified as overweight according to WHO Asia Pacific Classification of BMI. Therefore, it was well predicted that subjects who were overweight or obese on average had higher estradiol concentration, compared to the lean ones. Other factors that might affect estradiol concentration in postmenopausal women include psychological stress, presence of any other medical conditions that might induce hyperestrogenism such as malignancies, and use of medications such as antibiotics, antipsychotics, or anti-Parkinson drugs. These factors were not assessed in detail in our study and might be considered as confounding variables. . $^{13,14}$

Menopausal symptoms are thought to result from thermoregulatory dysfunction that is caused by gonadal hormones changes. ${ }^{15}$ Estrogens are wellknown neuromodulators of neuronal pathways throughout the central nervous system. ${ }^{11,15}$ In this study, menopausal symptoms such as hot flushes, sleep disruption, night sweats, and irritability, were mostly observed in the $\mathrm{MCl}$ group, which also had lower average levels of estradiol.

\section{Estradiol levels and menopausal symptoms}

Santoro et $\mathrm{al}^{12}$ reported that hot flushes were the most commonly reported menopausal symptom in postmenopausal women. It was present in $55 \%$ of women even before the onset of menstrual irregularity. Hot flushes are a symptom of human brain's response to diminished gonadal hormone concentrations and its fluctuations during menopausal transition. These gonadal hormones are believed to be important in the maintenance of the thermoregulatory mechanism in hypothalamus. ${ }^{16}$ Another study by Rossmanith et $\mathrm{al}^{11}$ discovered the "brain adaptation" process, which supported the hypothesis that most women adapted to a new hypoestrogenic state. Although hot flushes were known as the most frequently reported major symptom of menopause, $71.4 \%$ of subjects in this study presented no history of hot flushes. Statistical analysis also found that hot flushes and $\mathrm{MCl}$ were not significantly associated in this study. This implies that not every postmenopausal woman with $\mathrm{MCl}$ experiences hot flushes, and vice versa. This result differed from the findings reported by Ratka ${ }^{17}$, which found that the presence of hot flushes conveys a beneficial effect on the preservation of cognitive function in postmenopausal women. During the hypogonadal state, the human brain experiences a temporary insufficiency in glucose concentration. Hot flushes provide counterregulatory and self-defense mechanisms, which prevent the initiation of neurodegeneration due to the reduced glucose transport to the brain. This observation might explain why only a few menopausal women in Indonesia reported hot flashes, in line with earlier studies which reported incidence of hot flushes of $5.1 \%{ }^{18}$ 
Santoro et $\mathrm{al}^{12}$ reported that the prevalence of sleep difficulties increased by more than $50 \%$ in postmenopausal women. It also reported that hormonal changes were not the primary causes of sleep difficulty during the menopausal period. Our findings suggested that $66.7 \%$ of postmenopausal women who reported sleep disruptions had $\mathrm{MCl}$, and this association was statistically significant. Furthermore, sleep disruptions negatively correlated with estradiol levels, which means that subjects with lower estradiol levels experienced more sleep disruptions on average, compared to subjects with higher estradiol levels. Socio-economic status was also considered as an important social contributor to poor sleep quality, which consequently resulted in disadvantageous consequences including daytime fatigue and sleepiness. ${ }^{12}$ Therefore, poor sleep quality was considered as essential contributing factor to cognitive impairment in postmenopausal women. ${ }^{12}$

Apart from difficulties falling asleep and maintaining sleep, excessive night sweats may contribute to poor sleep quality in postmenopausal women. ${ }^{16}$ Data from a study by Utian ${ }^{16}$ reported that women experienced an average of three occurrences of excessive night sweats per week. This resulted in sleep disruptions and contributed to daytime irritability. However, only $24.8 \%$ of subjects in our study experienced night sweats, and $60.7 \%$ of subjects with night sweats had $\mathrm{MCl}$. Our study found no significant association between night sweats and $\mathrm{MCl}$ in postmenopausal women, which suggests that night sweats were not an important contributing factor to the development of $\mathrm{MCl}$ in postmenopausal women.

Mood changes in middle-aged women were thought to be associated with menopause through several mechanisms including elevated sensitivity to environmental events, altered hormone levels, and lifestyle factors. ${ }^{16}$ A study by Utian ${ }^{16}$ showed no consistent relationship between menopausal transition and increased risk of mood disorders. However, our study showed a significant relationship between irritability and $\mathrm{MCl}$ in postmenopausal women. Postmenopausal women who reported irritability were 1.96 times more likely to experience cognitive impairment than postmenopausal women without irritability. Statistical analysis also showed a negative correlation between irritability and estradiol levels in postmenopausal women. This suggests an inverse relationship between irritability and estradiol levels. Irritability was more frequently observed in subjects with lower estradiol concentrations, than in subjects with higher concentrations of estradiol.

During menopausal transition, it was observed that the association between estradiol variability and depressive symptoms was preceded in time by its effects on irritability, feelings of rejection to a psychosocial stressor, and stress-induced feelings of rejection. ${ }^{19}$ Depressive symptoms may also be associated with monoamine depletion which has been previously observed in menopausal women. ${ }^{20}$ Despite its findings, this study had several limitations that should be acknowledged. The first limitation was related to the study design itself. This study was a cross-sectional study. Therefore, a causal relationship between estradiol, menopausal symptoms, and $\mathrm{MCl}$ could not be established. In the future, longitudinal studies should be conducted to establish a true causeeffect relationship between these variables. Secondly, the total sample size of 245 postmenopausal women was considered small because it only represented $0.00175 \%$ of the 14 million postmenopausal women in Indonesia. Therefore, studies with greater sample sizes should be conducted in the future. Thirdly, several confounding factors related to the risk of developing $\mathrm{MCl}$ including nutritional intake, blood pressure, socioeconomic status, the use of certain medications, family history, psychological stressors, and physical activity, were not assessed in this study. Therefore, results of this study might have been influenced by these confounders.

It may be concluded that low estradiol levels were associated with higher risks of menopausal symptom and developing $\mathrm{MCl}$ in menopausal women. Of all the variables assessed in our study, sleep disruption and estradiol levels were the most influential factors in the development of $\mathrm{MCl}$ in postmenopausal women.

\section{Conflicts of Interest}

The authors confirm there are no conflicts of interests in this study.

Acknowledgment

None.

Funding Sources

None.

\section{REFERENCES}

1. Amore M, Di Donato P, Berti A, Palareti A, Chirico C, Papalini $A$, et al. Sexual and psychological symptoms in the climacteric years. Maturitas. 2007;56(3):303-11. 
2. Takahashi T, Johnson KM. Menopause. Med Clin North Am. 2015;99(3):521-34.

3. Pimenta F, Leal I, Maroco J, Ramos C. Menopausal symptoms: do life events predict severity of symptoms in peri- and postmenopause? Maturitas. 2012;72(4):324-31.

4. Lambert MN, Thorup AC, Hansen ES, Jeppesen PB. Combined red clover isoflavones and probiotics potently reduce menopausal vasomotor symptoms. PLoS One. 2017;12(6):0176590.

5. Hestiantoro A, Wiwie M, Shadrina A, Ibrahim N, Purba JS. FSH to estradiol ratio can be used as screening method for mild cognitive impairment in postmenopausal women. Climacteric. 2017;20(6):577-82.

6. Henderson VW. Three midlife strategies to prevent cognitive impairment due to Alzheimer's disease. Climacteric. 2014;17:38-46.

7. Henderson VW. Cognitive changes after menopause: influence of estrogen. Clin Obstet Gynecol. 2008;51(3):618-26.

8. Nasrun MWS. Buku pedoman skoring: Hendaya Kognitif Non Demensia (HKND) pada Populasi "Brain at Risk" bagi Praktisi Kesehatan. Jakarta, Indonesia: Pusat Penerbitan Departemen Ilmu Penyakit Dalam; 2007. Indonesian.

9. Dalal PK, Agarwal M. Postmenopausal syndrome. Indian J Psychiatry. 2015;57(Suppl 2):S222-32.

10. Zeki Al Hazzouri A, Stone KL, Haan MN, Yaffe K. Leptin, mild cognitive impairment, and dementia among elderly women. J Gerontol A Biol Sci Med Sci. 2013;68(2):175-80.

11. Rossmanith W, Ruebberrdt W. What causes hot flushes? the neuroendocrine origin of vasomotor symptoms in the menopause. Gynecol Endocrinol. 2009;25(5):303-14.

12. Santoro N, Epperson CN, Mathews SB. Menopausal symptoms and their management. Endocrinol Metab Clin North Am. 2015;44(3):497-515.

13. Nelson LR, Bulun SE. Estrogen production and action. J Am Acad Dermatol. 2001;45(3 Suppl):S116-24

14. Grantham JP, Henneberg $M$. The estrogen hypothesis of obesity. PLoS One. 2014;9(6):eg9776.

15. Deecher DC, Dorries K. Understanding the pathophysiology of vasomotor symptoms (hot flushes and night sweats) that occur in perimenopause, menopause, and postmenopause life stages. Arch Womens Ment Health. 2007;10(6):247-57.

16. Utian WH. Psychosocial and socioeconomic burden of vasomotor symptoms in menopause: a comprehensive review. Health Qual Life Outcomes. 2005;3:47.

17. Ratka A. Menopausal hot flashes and development of cognitive impairment. Ann N Y Acad Sci. 2005;1052:11-26.

18. Haines CJ, Xing SM, Park KH, Holinka CF, Ausmanas MK. Prevalence of menopausal symptoms in different ethnic groups of Asian women and responsiveness to therapy with three doses of conjugated estrogens/medroxyprogesterone acetate: the Pan-Asia Menopause (PAM) study. Maturitas. 2005;52(34):264-76.

19. Gordon JL, Rubinow DR, Eisenlohr-Moul TA, Leserman J, Girdler SS. Estradiol variability, stressful life events, and the emergence of depressive symptomatology during the menopausal transition. Menopause. 2016;23(3):257-66.

20. Newhouse PA, Dumas J, Wilkins H, Coderre E, Sites CK, Naylor $M$, et al. Estrogen treatment impairs cognitive performance after psychosocial stress and monoamine depletion in postmenopausal women. Menopause. 2010;17(4):860-73. 